\title{
COLESTEROL EM REFEIÇÕES COMERCIAIS CONSUMIDAS NA CIDADE DE LONDRINA (PR), BRASIL
}

\author{
SUZANA LUCY NIXDORF * \\ MAKOTO MATSUSHITA ** \\ NILSON EVELÁZIO DE SOUZA ***
}

\begin{abstract}
Testou-se método para determinação de colesterol em amostras de refeições freqüentemente consumidas em restaurantes da cidade de Londrina (PR). As análises de colesterol foram realizadas por cromatografia em fase gasosa utilizando detector de ionização de chama e coluna capilar. As 119 amostras analisadas apresentaram teores médios de colesterol que variaram de níveis não detectáveis a $86,69 \mathrm{mg} / 100 \mathrm{~g}$, para espaguete alho e óleo e picanha, respectivamente. A precisão do método foi avaliada pela análise de feijoada em 10 repetições e apresentou desvio padrão de 1,26\% e coeficiente de variação de $2,90 \%$. Concluiu-se que o método testado para determinação de colesterol em alimentos, utilizando coluna capilar em substituição a coluna empacotada, apresentou boa reprodutibilidade e recuperação. Refeições a base de carne foram as que apresentaram maiores teores de colesterol.
\end{abstract}

\section{INTRODUÇÃO}

Colesterol $\left(\mathrm{C}_{27} \mathrm{H}_{46} \mathrm{O}\right)$ é um dos mais importantes esteróis encontrados nos tecidos animais. Apesar de insolúvel em água é facilmente extraído de tecidos com clorofórmio, éter etílico, éter de petróleo, benzeno ou álcool etílico à quente. É praticamente inexistente nos vegetais, ocorrendo apenas raramente em plantas superiores, as quais contém outros tipos de esteróis, conhecidos como fitosteróis $(4,6)$.

* Professores do Departamento de Química da Universidade Estadual de Londrina.

** Doutor em Ciências Ambientais, Professor de Química e Tecnologia de Alimentos do Departamento de Química da Universidade Estadual de Maringá.

*** Doutor em Química Analítica, Pesquisador IIB do CNPq (Área de Alimentos), Professor do Departamento de Química da Universidade Estadual de Maringá. 
Diversas são as origens do colesterol no organismo humano. Esta substância pode tornar-se perigosa e letal se houver desequilíbrio no organismo, provocado não somente por fatores de risco, mas também por problemas genéticos, tais como, defeitos dos receptores LDL (lipoproteínas de baixa densidade) e falta ou excesso de certas enzimas que regulam o metabolismo $(6,7)$.

É conveniente ressaltar a necessidade e importância de colesterol e de triacil-gliceróis para o organismo humano. O colesterol não pode ser totalmente banido da alimentação, porque em níveis médios é um produto necessário ao organismo (4).

Os lipídios são responsáveis pelo armazenamento de 95\% de energia e o colesterol é essencial para a produção de ácidos biliares (cólico, quenodesoxicólico, desoxicólico e litocólico), que auxiliarão na digestão destes lipídios. Além disso, é o precursor dos hormônios sexuais (testosterona, androsterona, progesterona, estradiol), além de ser um dos principais formadores das membranas do corpo e apresentar propriedades anti-inflamatória (cortisona), cardiotônica (digitoxigenina) e anti-raquítica (vitamina D) $(5,6)$.

O colesterol pode estar presente na forma livre ou esterificado com ácidos graxos, podendo formar complexos com lipoproteínas e fosfolipídios. O colesterol é citado como um dos fatores associados à ocorrência de aterosclerose, portanto alimentos como carnes, ovos e leite podem aumentar o nível de colesterol no sangue. Entretanto outros componentes da dieta também podem resultar em efeitos semelhantes como por exemplo gorduras e açúcares. Pesquisadores têm verificado maior correlação entre doenças coronarianas, em função da existência de triglicerídios no sangue, resultado do consumo de óleos saturados e açúcares do que pela presença de colesterol (9).

O conteúdo de colesterol na dieta afeta distintamente o nível de colesterol sangüíneo em diferentes espécies. Assim, em coelhos e pintainhos, o nível de colesterol sangüíneo sobe rapidamente com 0 aumento da concentração na dieta, o que não se observa em outras espécies como rato e cão. Da mesma forma, no homem, dietas com pequenas variações no conteúdo de colesterol parecem não afetar significativamente o nível de colesterol no sangue (10).

Concentrações mais altas de colesterol são encontradas em tecidos do sistema nervoso, fígado e em gorduras depositadas (3). Em excesso, passa a se acumular nas paredes das artérias. É transportado na corrente sangüínea por substâncias denominadas lipoproteínas de baixa densidade (LDL) e lipoproteínas de alta densidade (HDL). A primeira está associada com o desenvolvimento da aterosclerose e a segunda retira a gordura de circulação e auxilia o organismo na sua eliminação $(8,13,14)$. 
O National Cholesterol Education Program - Dietary Advice, recomenda teor de colesterol no sangue humano menor que $200 \mathrm{mg} / \mathrm{dL}$ e o LDL menor que $130 \mathrm{mg} / \mathrm{dL}$ para o indivíduo do sexo masculino que apresentar um ou mais dos seguintes fatores de risco: hipertensão, obesidade, diabétes, histórico familiar com enfermidades coronarianas e fumante. Se o LDL for maior que $130 \mathrm{mg} / \mathrm{dL}$ deve-se reduzir a ingestão do colesterol para 300 $\mathrm{mg} / \mathrm{dia}$, gordura saturada para 10\% do valor calórico total (VCT) e lipídios totais para $30 \%$ do VCT. Se não obtiver sucesso, aconselha-se reduzir a ingestão de gordura saturada para $7 \%$ do VCT e de colesterol para 200 mg/dia durante 6 meses (14). Nota-se assim, a importância de se ter conhecimento dos teores de colesterol em alimentos.

Preocupações recentes com o papel do colesterol têm exigido a necessidade de metodologia rápida, exata e precisa para determinação de colesterol em alimentos, a partir de resíduo insaponificável (1), sendo aceita a cromatografia em fase gasosa como método ideal para este tipo de determinação $(11,12)$.

O objetivo deste trabalho foi determinar o teor de colesterol em amostras de refeições comerciais consumidas na cidade de Londrina (PR), utilizando-se a técnica de cromatografia em fase gasosa com coluna capilar.

\section{MATERIAIS E MÉTODOS}

\subsection{AMOSTRAGEM}

Foram efetuadas três amostragens, aleatoriamente, em 15 restaurantes da cidade de Londrina (PR), para 11 tipos de refeições: comida chinesa (frango xadrez e carne com legumes), massas (lasanha e espaguete alho e óleo), a la carte (picanha e strogonoff), carnes (rodízio de carnes) e diversos (feijoada, moqueca de peixe, maionese e prato comercial composto por arroz, feijão, bife e salada). Cada amostra foi analisada em triplicata.

\subsection{REAGENTES}

Utilizou-se colesterol padrão, Sigma, EUA (mínimo 99\%); 5- $\alpha$-colestano padrão, Sigma, EUA (mínimo 99\%); etanol absoluto PA-ACS (mínimo 99\%); metanol absoluto PA-ACS (mínimo 99\%); isopropanol absoluto PAACS (mínimo 99\%); hexano PA-ACS; hidróxido de potássio PA-ACS e sulfato de sódio anidro PA-ACS. 


\subsection{EQUIPAMENTOS E CONDIÇÕES DE OPERAÇÃO}

Foi utilizado cromatógrafo à gás Shimadzu CGS-14A (Japão), equipado com detector de ionização de chama e coluna capilar de sílica fundida com $25 \mathrm{~m}$ de comprimento e $0,25 \mathrm{~mm}$ de diâmetro, contendo $0,20 \mu \mathrm{m}$ de SE30. O fluxo do gás de arraste, nitrogênio ultra-puro, foi de $30 \mathrm{~mL} / \mathrm{min}$, temperatura da coluna de $300^{\circ} \mathrm{C}$, temperatura do injetor de $245^{\circ} \mathrm{C}$ e, temperatura do detector de $300^{\circ} \mathrm{C}$.

\subsection{METODOLOGIA}

Utilizou-se a técnica de extração e análise de colesterol, segundo ALHASANI et al. (1), com modificações. As amostras de refeições foram trituradas em multiprocessador e pesadas, cerca de 5-10 g $( \pm 0,001 \mathrm{~g})$ em frascos de vidro para refluxo. À cada amostra foi adicionada mistura alcoólica (etanol + metanol + isopropanol, 90:5:5, v/v/v) em quantidade equivalente a $4,0 \mathrm{~mL} / \mathrm{g}$ de amostra, seguida de solução aquosa a $60 \%$ de $\mathrm{KOH}$ na proporção $1,0 \mathrm{~mL} / \mathrm{g}$ de amostra, mantida sob refluxo por 30 minutos, com agitação magnética contínua. Após resfriamento a temperatura ambiente, acrescentou-se $100,0 \mathrm{~mL}$ de hexano, mantendo o frasco fechado sob agitação magnética por 10 minutos. A seguir foram adicionados $25,0 \mathrm{~mL}$ de água deionizada, mantendo-se agitação por mais 15 minutos. Após decantação, 25,0 mL da fase superior orgânica foi filtrada em sulfato de sódio anidro e o solvente evaporado em corrente de nitrogênio, até secagem total. O resíduo foi dissolvido em $2,0 \mathrm{~mL}$ de hexano contendo $0,20 \mathrm{mg} / \mathrm{mL}$ de 5 - $\alpha$-colestano e, cerca de $2 \mu \mathrm{L}$ injetado no cromatógrafo à gás com coluna capilar, para análise do colesterol.

\subsection{CÁLCULO DA CONCENTRAÇÃO DO COLESTEROL}

A quantificação do colesterol nas amostras foi efetuada conforme ALHASANI et al. (1), com modificações.

Preparou-se soluções do padrão colesterol em hexano nas concentrações 0,$10 ; 0,20 ; 0,30 ; 0,50 ; 0,75$ e $1,00 \mathrm{mg} / \mathrm{mL}$, contendo em cada uma, 0,20 $\mathrm{mg} / \mathrm{mL}$ do padrão interno 5 - $\alpha$-colestano. Construiu-se gráfico plotando a concentração de colesterol versus a razão das áreas dos picos de $5-\alpha-$ colestano e de colesterol.

Para o cálculo do teor de colesterol nas amostras foi utilizada a razão das áreas dos picos de 5- $\alpha$-colestano e de colesterol, verificando-se através do gráfico, a concentração de colesterol. Os cálculos foram efetuados levando-se em consideração o volume injetado, o volume do extrato e a massa da amostra. Quando a resposta cromatográfica da amostra 
apresentou-se maior que a do padrão, a solução amostra foi diluída e, quando menor, concentrada por evaporação.

\section{RESULTADOS E DISCUSSÃO}

A precisão do método foi medida utilizando-se uma amostra de feijoada analisada 10 vezes (Tabela 1 ).

\section{TABELA 1 - PRECISÃO DO MÉTODO AVALIADA ATRAVÉS DA ANÁLISE DE AMOSTRA DE FEIJOADA}

\begin{tabular}{c|c|c|c|c}
\hline Análises & $\begin{array}{c}\text { Colesterol } \\
(\mathrm{mg} / 100 \mathrm{~g})\end{array}$ & Média & Desvio Padrão & $\begin{array}{c}\text { Coeficiente de } \\
\text { Variança (\%) }\end{array}$ \\
\hline 1 & 42,13 & & & \\
2 & 41,89 & & & \\
3 & 40,11 & & & \\
4 & 42,42 & & & \\
5 & 43,02 & & & \\
6 & 41,55 & 42,28 & 1,26 & \\
7 & 44,23 & & & \\
8 & 42,58 & & & \\
9 & 41,11 & & & \\
10 & 43,78 & & & \\
\hline
\end{tabular}

A principal modificação efetuada no método de AL-HASANI et al. (1) foi a utilização de coluna capilar, a qual apresenta maior número de pratos de separação em relação à coluna empacotada e conseqüentemente maior eficiência e menor sangria. Os resultados das 10 analises de feijoada variaram de 40,11 a 44,23 mg/100 g, com valor médio de 42,28 $\pm 1,26$ e coeficiente de variança de 2,90\%. O coeficiente de variança de $2,90 \%$ obtido, evidencia precisão inferior à obtida por AL-HASANI et al. (1), que analisou a precisão do método, utilizando carne cozida, alimento bem mais homogêneo do que a feijoada.

Em relação a recuperação do método foram adicionados 25 e $50 \mathrm{mg} / \mathrm{mL}$ de colesterol em 5 amostras de de feijoada, cujos resultados são apresentados nas Tabelas 2 e 3. 
A percentagem de recuperação do método para adição de 25 e $50 \mathrm{mg} / \mathrm{mL}$ de colesterol à amostra de feijoada foi da mesma ordem que a obtida por AL-HASANI et al. (1).

\section{TABELA 2 - RECUPERAÇÃO DO MÉTODO COM ADIÇÃO DE $25 \mathrm{mg} / \mathrm{mL}$ DE COLESTEROL EM AMOSTRA DE FEIJOADA}

\begin{tabular}{c|c|c|c|c}
\hline Análises & $\begin{array}{c}\text { Recuperação } \\
(\%)\end{array}$ & $\begin{array}{c}\text { Recuperação } \\
\text { Média }\end{array}$ & Desvio Padrão & $\begin{array}{c}\text { Coeficiente de } \\
\text { Variança (\%) }\end{array}$ \\
\hline 1 & 97,8 & & & \\
2 & 96,3 & & 1,7 & 1,7 \\
3 & 99,8 & 98,6 & & \\
4 & 98,7 & & & \\
5 & 100,5 & & & \\
\hline
\end{tabular}

TABELA 3 - RECUPERAÇÃO DO MÉTODO COM ADIÇÃO DE $50 \mathrm{mg} / \mathrm{mL}$ DE COLESTEROL EM AMOSTRA DE FEIJOADA

\begin{tabular}{c|c|c|c|c}
\hline Análises & $\begin{array}{c}\text { Recuperação } \\
\text { (\%) }\end{array}$ & $\begin{array}{c}\text { Recuperação } \\
\text { Média }\end{array}$ & Desvio Padrão & $\begin{array}{c}\text { Coeficiente de } \\
\text { Variança (\%) }\end{array}$ \\
\hline 1 & 100,1 & & & \\
2 & 99,0 & & & 1,4 \\
3 & 98,1 & 99,1 & & \\
4 & 97,5 & & & \\
5 & 101,0 & & & \\
\hline
\end{tabular}

$\mathrm{Na}$ Tabela 4 são apresentados os resultados para colesterol nas 11 refeições, analisadas em triplicatas e procedentes de três diferentes restaurantes da cidade de Londrina (PR). Os resultados variaram desde níveis não detectados para uma das amostras de espaguete alho e óleo a $86,69 \pm 2,92 \mathrm{mg} / 100 \mathrm{~g}$ (picanha). Observou-se que os pratos que apresentaram menor variação foram o rodízio de carnes e a picanha. Possivelmente porque estes dois pratos são matrizes mais simples e menos manipuladas quando comparadas às demais refeições. Outra razão pode estar no fato de que a picanha adquirida pelos restaurantes tem praticamente sempre $20 \%$ de gordura. No caso do rodízio de carnes, procurou-se manter sempre a mesma proporção ao se coletar as amostras, sendo que as determinações representam a média da descrição apresentada na Tabela 4. 
TABELA 4 - TEORES DE COLESTEROL (mg/100 g) EM ONZE REFEIÇõES COMERCIAIS, COLETADAS EM TRÊS DIFERENTES RESTAURANTES DA CIDADE DE LONDRINA (PR)

\begin{tabular}{|c|c|c|c|c|}
\hline \multirow[b]{2}{*}{ PRATOS/REFEIÇÕES } & \multicolumn{4}{|c|}{ TEORES DE COLESTEROL (mg/100 g) } \\
\hline & RESTAURANTE 1 & RESTAURANTE 2 & RESTAURANTE 3 & VALOR MÉDIO \\
\hline $\begin{array}{l}\text { FRANGO XADREZ (600 g de peito de frango; } 1 \text { pimentão vermelho; } 1 \text { pimentão } \\
\text { verde; } 1 / 2 \text { xícara de amendoim; shoyu; vinagre; sal e óleo) }\end{array}$ & $31,50 \pm 0,30$ & $38,30 \pm 2,10$ & $36,31 \pm 2,10$ & $36,31 \pm 3,95$ \\
\hline $\begin{array}{l}\text { CARNE COM LEGUMES ( } 300 \mathrm{~g} \text { de costelinha de porco; } 1 / 2 \text { cebola; } 6 \text { ervilhas tortas; } \\
\text { 1/2 pimentão; } 1 \text { cenoura; } 1 / 2 \text { colher de maizena e } 1 \text { colher de óleo) }\end{array}$ & $41,43 \pm 2,12$ & $36,43 \pm 2,41$ & $40,58 \pm 1,60$ & $39,48 \pm 2,87$ \\
\hline $\begin{array}{l}\text { LASANHA (1 pacote de massa de lasanha; } 4 \text { xícaras de molho de tomate; } 3 \text { copos de } \\
\text { leite; } 400 \mathrm{~g} \text { de mossarela e } 400 \mathrm{~g} \text { de presunto) }\end{array}$ & $33,38 \pm 1,92$ & $37,82 \pm 1,52$ & $44,12 \pm 0,90$ & $38,44 \pm 4,96$ \\
\hline $\begin{array}{l}\text { ESPAGUETE ALHO E ÓLEO (250 g de macarrão; } 2 \text { colheres de óleo e } 2 \text { dentes de } \\
\text { alho) }\end{array}$ & $30,25 \pm 0,91$ & $15,69 \pm 0,33$ & ND & $15,35 \pm 13,58$ \\
\hline PICANHA & $85,82 \pm 2,11$ & $88,69 \pm 2,92$ & $82,10 \pm 1,30$ & $85,54 \pm 3,41$ \\
\hline $\begin{array}{l}\text { STROGONOFF ( } 2 \mathrm{~kg} \text { de filé mignon; } 1 \text { lata de creme de leite; } 2 \text { copos de champignon; } \\
3 \text { cebolas batidas; } 2 \text { tomates e } 1 \text { xícara de catchup) }\end{array}$ & $47,20 \pm 0,28$ & $48,31 \pm 0,81$ & $43,73 \pm 1,39$ & $46,41 \pm 2,26$ \\
\hline $\begin{array}{l}\text { RODÍZIO DE CARNES (picanha 25\%; alcatra 15\%; filé mignon 15\%; costela, cupim, } \\
\text { lombo, frango, coração e outros 45\%) }\end{array}$ & $85,36 \pm 2,48$ & $81,34 \pm 2,19$ & $84,28 \pm 1,82$ & $83,65 \pm 2,52$ \\
\hline $\begin{array}{l}\text { FEIJOADA ( } 2 \mathrm{~kg} \text { de feijão preto; } 1 \mathrm{~kg} \text { de carne seca; } 1 / 2 \mathrm{~kg} \text { de costela fresca; } 1 \mathrm{~kg} \text { de } \\
\text { linguiiça; } 400 \mathrm{~g} \text { de paio; } 200 \mathrm{~g} \text { de bacon; } 2^{1 / 2} \mathrm{~kg} \text { de mídos de porco (pé, rabo, } \\
\text { orelha, etc); } 3 \text { cebolas; pimenta do reino; sal e louro) }\end{array}$ & $47,85 \pm 0,39$ & $33,81 \pm 0,91$ & $41,84 \pm 0,38$ & $41,17 \pm 6,31$ \\
\hline $\begin{array}{l}\text { MOQUECA DE PEIXE ( } 1 \mathrm{~kg} \text { de posta de peixe; } 4 \text { tomates; } 2 \text { cebolas; } 2 \text { pimentões; } 1 \\
\text { xícara de leite de coco } \mathrm{e}^{1 / 2} \text { xícara de azeite de dendê) }\end{array}$ & $25,53 \pm 1,21$ & $25,02 \pm 0,38$ & $22,11 \pm 0,32$ & $24,15 \pm 2,04$ \\
\hline $\begin{array}{l}\text { MAIONESE (500 g de batata; } 150 \mathrm{~mL} \text { de óleo; } 1 \text { ovo; } 2 \text { colheres de vinagre; sal e } \\
\text { pimenta) }\end{array}$ & $36,51 \pm 2,18$ & $34,83 \pm 1,52$ & $67,88 \pm 2,02$ & $46,41 \pm 16,71$ \\
\hline PRATO COMERCIAL (140 g de arroz; $80 \mathrm{~g}$ de feijão; $80 \mathrm{~g}$ de carne e $50 \mathrm{~g}$ de salada) & $17,32 \pm 1,87$ & $15,20 \pm 2,12$ & $8,79 \pm 0,81$ & $13,76 \pm 4,20$ \\
\hline
\end{tabular}

Os resultados são médias de três amostras analisadas em triplicatas. 
As outras refeições, que são compostas por maior número de ingredientes, produziram maior variação nos resultados, talvez como reflexo das diferentes receitas adotadas pelos restaurantes. As maiores variações ocorreram no prato comercial, na maionese e no espaguete alho e óleo, respectivamente. A razão destas variações deve-se ao fato de que no prato comercial, os ingedientes não foram pesados, sendo a porção de carne, arroz, feijão e salada feita por aproximação. Assim, a variação na composição do prato pode ter produzido variações nos resultados. A variação no teor de colesterol da maionese foi verificada principalmente em função da receita utilizada. Na receita caseira são utilizadas duas gemas de ovos, o que contribui significativamente para o resultado final. $O$ espaguete alho e óleo sofreu maior variação, a qual pode ser explicada pela utilização de diferentes tipos de massas de macarrão, ou seja, macarrão com ovos em receita caseira, macarrão com ovos em massas industrialmente comercializadas e macarrão de semôla, que não apresenta ovos em sua composição. Estes dados mostram que apenas uma refeição diária à base de carnes, atinge os níveis de colesterol recomendados para ingestão diária, e que a popular feijoada brasileira não atinge estes níveis. Cabe lembrar, no entanto, que os níveis de colesterol no sangue não dependem somente do conteúdo de colesterol dos alimentos, mas também do balanço de ácidos graxos saturados e insaturados (2).

\title{
4 CONCLUSÃO
}

O método testado para determinação de colesterol em alimentos utilizando coluna capilar em substituição a coluna empacotada apresentou boa reprodutibilidade e recuperação. Refeições a base de carne foram as que apresentaram maiores teores de colesterol.

\begin{abstract}
A rapid method with modifications for cholesterol determination was applied in mea samples frequently consumed in restaurants of Londrina, Paraná State, Brazil. Analyses of cholesterol were performed by gas chromatography, with flame ionization detector and capillary column. In 119 samples assays the cholesterol content ranged from non detectable levels to $88.60 \mathrm{mg}$ per $100 \mathrm{~g}$ respectively in the spaghetti garlic and oil and "picanha". To examine the aforementioned criteria, the feijoada samples were analyzed ten times to measure the precision and presented $1.26 \%$ standard deviation with $2.90 \%$ variance coefficient. The applied method for cholesterol determination in food samples, handling capillary column instead of pocked column, developed high reproductibility. Meals based on meat had the highest cholesterol levels.
\end{abstract}




\section{REFERÊNCIAS BIBLIOGRÁFICAS}

1 AL-HASANI, S. M., HIAVAC, J., CARPENTER, M. W. Rapid determination of cholesterol in single and multicomponent prepared foods. J. Assoc. Off. Anal. Chem. Int., v. 76, n. 4, p. 902-906, 1993.

2 ANDERSON, J. T., GRANDE, F., KEYS, A. Cholesterol-lowering diets. J. Am. Diet Assoc., v. 62, p. 133-142, 1973.

3 BOBBIO, F. O., BOBBIO, P. A. Introdução à química de alimentos. 2. ed. São Paulo : Varela, 1989.

4 CHAMIZO, J. A. Brain tinglers. J. Chem. Ed., v. 59, n. 2, p. 151-159, 1982.

5 FENTON, M. Chromatographic separation of cholesterol in foods. J. Chromatogr., v. 624, p. 369-388, 1992.

6 LEHNINGER, A. L., NELSON, D. L., COX, M. M. Princípios de Bioquímica. 2. ed. São Paulo : Sarvier, 1995.

7 MONTGOMERY, R., CONWAY, T. W., SPECTOR, A. A. Bioquímica: uma abordagem dirigida por casos. 5. ed. São Paulo : Artes Médicas, 1994.

8 PEREIRA, L. E., PAPAROUNIS, D., CONTRERAS, E. Coração, a máquina da vida. Rev. Saúde, v. 10, n. 10, p. 34-55, 1993.

9 POTTER, N. N. Food science. 2. ed. Westport : AVI Publishers, 1973.

10 SGARBIERI, V. C. Alimentação e nutrição: fator de saúde e desenvolvimento. Campinas : Ed. Unicamp, 1987.

11 SHEPPARD, A. J., NEWKIRK, D. R., HUBBARD, W. D., OSGOOD, T., FENTON, M. Chromatographic separation of cholesterol in foods. J. Chromatogr., v. 624, p. 369-388, 1992.

SWEENEY, J. P., WEEIRAUCH, J. L., FENTON, M. Chromatographic separation of cholesterol in foods. J. Chromatogr., v. 624, p. 369388, 1992.

13 TAVARES, M. A expressão "sem colesterol" contida nas embalagens de óleos e gorduras vegetais: uma propaganda enganosa? B. Inst. Adolfo Lutz, v. 2, p. 6, 1992. 
14 WARDLAN, G. M., INSEL, P. M. Perspectives in nutrition. 2. ed. Missouri : Mosby Year Book, 1993. 
TABELA 4 - TEORES DE COLESTEROL (mg/100 g) EM ONZE REFEIÇõES COMERCIAIS, COLETADAS EM TRÊS DIFERENTES RESTAURANTES DA CIDADE DE LONDRINA (PR)

\begin{tabular}{|c|c|c|c|c|}
\hline \multirow[b]{2}{*}{ PRATOS/REFEIÇÕES } & \multicolumn{4}{|c|}{ TEORES DE COLESTEROL (mg/100 g) } \\
\hline & RESTAURANTE 1 & RESTAURANTE 2 & RESTAURANTE 3 & VALOR MÉDIO \\
\hline $\begin{array}{l}\text { FRANGO XADREZ (600 g de peito de frango; } 1 \text { pimentão vermelho; } 1 \text { pimentão } \\
\text { verde; } 1 / 2 \text { xícara de amendoim; shoyu; vinagre; sal e óleo) }\end{array}$ & $31,50 \pm 0,30$ & $38,30 \pm 2,10$ & $36,31 \pm 2,10$ & $36,31 \pm 3,95$ \\
\hline $\begin{array}{l}\text { CARNE COM LEGUMES ( } 300 \mathrm{~g} \text { de costelinha de porco; } 1 / 2 \text { cebola; } 6 \text { ervilhas tortas; } \\
\text { 1/2 pimentão; } 1 \text { cenoura; } 1 / 2 \text { colher de maizena e } 1 \text { colher de óleo) }\end{array}$ & $41,43 \pm 2,12$ & $36,43 \pm 2,41$ & $40,58 \pm 1,60$ & $39,48 \pm 2,87$ \\
\hline $\begin{array}{l}\text { LASANHA (1 pacote de massa de lasanha; } 4 \text { xícaras de molho de tomate; } 3 \text { copos de } \\
\text { leite; } 400 \mathrm{~g} \text { de mossarela e } 400 \mathrm{~g} \text { de presunto) }\end{array}$ & $33,38 \pm 1,92$ & $37,82 \pm 1,52$ & $44,12 \pm 0,90$ & $38,44 \pm 4,96$ \\
\hline $\begin{array}{l}\text { ESPAGUETE ALHO E ÓLEO (250 g de macarrão; } 2 \text { colheres de óleo e } 2 \text { dentes de } \\
\text { alho) }\end{array}$ & $30,25 \pm 0,91$ & $15,69 \pm 0,33$ & ND & $15,35 \pm 13,58$ \\
\hline PICANHA & $85,82 \pm 2,11$ & $88,69 \pm 2,92$ & $82,10 \pm 1,30$ & $85,54 \pm 3,41$ \\
\hline $\begin{array}{l}\text { STROGONOFF ( } 2 \mathrm{~kg} \text { de filé mignon; } 1 \text { lata de creme de leite; } 2 \text { copos de champignon; } \\
3 \text { cebolas batidas; } 2 \text { tomates e } 1 \text { xícara de catchup) }\end{array}$ & $47,20 \pm 0,28$ & $48,31 \pm 0,81$ & $43,73 \pm 1,39$ & $46,41 \pm 2,26$ \\
\hline $\begin{array}{l}\text { RODÍZIO DE CARNES (picanha 25\%; alcatra 15\%; filé mignon 15\%; costela, cupim, } \\
\text { lombo, frango, coração e outros 45\%) }\end{array}$ & $85,36 \pm 2,48$ & $81,34 \pm 2,19$ & $84,28 \pm 1,82$ & $83,65 \pm 2,52$ \\
\hline $\begin{array}{l}\text { FEIJOADA ( } 2 \mathrm{~kg} \text { de feijão preto; } 1 \mathrm{~kg} \text { de carne seca; } 1 / 2 \mathrm{~kg} \text { de costela fresca; } 1 \mathrm{~kg} \text { de } \\
\text { linguiiça; } 400 \mathrm{~g} \text { de paio; } 200 \mathrm{~g} \text { de bacon; } 2^{1 / 2} \mathrm{~kg} \text { de mídos de porco (pé, rabo, } \\
\text { orelha, etc); } 3 \text { cebolas; pimenta do reino; sal e louro) }\end{array}$ & $47,85 \pm 0,39$ & $33,81 \pm 0,91$ & $41,84 \pm 0,38$ & $41,17 \pm 6,31$ \\
\hline $\begin{array}{l}\text { MOQUECA DE PEIXE ( } 1 \mathrm{~kg} \text { de posta de peixe; } 4 \text { tomates; } 2 \text { cebolas; } 2 \text { pimentões; } 1 \\
\text { xícara de leite de coco } \mathrm{e}^{1 / 2} \text { xícara de azeite de dendê) }\end{array}$ & $25,53 \pm 1,21$ & $25,02 \pm 0,38$ & $22,11 \pm 0,32$ & $24,15 \pm 2,04$ \\
\hline $\begin{array}{l}\text { MAIONESE (500 g de batata; } 150 \mathrm{~mL} \text { de óleo; } 1 \text { ovo; } 2 \text { colheres de vinagre; sal e } \\
\text { pimenta) }\end{array}$ & $36,51 \pm 2,18$ & $34,83 \pm 1,52$ & $67,88 \pm 2,02$ & $46,41 \pm 16,71$ \\
\hline PRATO COMERCIAL (140 g de arroz; $80 \mathrm{~g}$ de feijão; $80 \mathrm{~g}$ de carne e $50 \mathrm{~g}$ de salada) & $17,32 \pm 1,87$ & $15,20 \pm 2,12$ & $8,79 \pm 0,81$ & $13,76 \pm 4,20$ \\
\hline
\end{tabular}

Os resultados são médias de três amostras analisadas em triplicatas. 